\title{
Análise da adequação de embalagens de medicamentos fitoterápicos comercializados em uma drogaria da cidade de Manaus-AM
}

Analysis of the adequacy of herbal medicine packaging sold in a drugstore in the city of Manaus-AM Análisis de la adecuación de los envases de fitoterapia vendidos en una farmacia de la ciudad de Manaus-AM

Pâmela Maria Reis dos Santos ORCID: https://orcid.org/0000-0002-7351-6505 Universidade Nilton Lins, Brasil

E-mail: reispamela015@gmail.com

Gabriel Oliveira de Souza

ORCID: https://orcid.org/0000-0001-9168-074X Universidade Nilton Lins, Brasil

E-mail: gabriel.souza@uniniltonlins.edu.br

\begin{abstract}
Resumo
Nos últimos anos, o consumo de plantas medicinais e medicamentos fitoterápicos experimentou um notável aumento de consumo na sociedade brasileira. Isto dever-se ao fato da seguridade demonstrada por estudos clínicos a sua eficácia no tratamento de determinadas patologias. Além da percepção da segurança destes produtos junto aos prescritores e sociedade leiga, ao mesmo tempo estão cada vez mais presentes em farmácias e drogarias, aumento o arsenal terapêutico desses estabelecimentos. Este estudo tem como objetivo procurar analisar os rótulos de medicamentos fitoterápicos comercializados em uma drogaria da cidade de Manaus-AM, em relação ao preconizado pela legislação vigente da Anvisa. O presente estudo trata-se de uma pesquisa de amostragem com análise comparativa de dados de 35 medicamentos fitoterápicos, utilizando dados publicados pela Anvisa referentes a rotulação de medicamentos fitoterápicos. O presente estudo demonstrou que nem todos os medicamentos seguem a padronização da Anvisa uma vez que em grande parte não se possui o sistema de Braille que faz com que pessoas com deficiência visual não consigam ter acesso. Os dados apresentados mostram uma quantidade expressiva de marcas de medicamentos fitoterápicos não atendem a essa essencial demanda, ou seja, a garantia do acesso dos deficientes visuais a terapêutica segura e racional dos medicamentos fitoterápicos, sendo somente $29 \%$ dos medicamentos analisados compatíveis com o preconizado pela legislação da ANVISA. Trabalhos como esse tem um importante papel fiscalizados nas demandas sociais, e deveriam ser mais explorados, uma vez que prestam um imenso serviço de fiscalização aos órgãos reguladores e a sociedade leiga.
\end{abstract}

Palavras-chave: Medicamentos fitoterápicos; Farmácia; Rotulagem; Fitoterápicos.

\begin{abstract}
In recent years, the consumption of medicinal plants and herbal medicines has experienced a notable increase in consumption in Brazilian society. This is due to the fact that the safety demonstrated by clinical studies is its effectiveness in the treatment of certain pathologies. In addition to the perception of safety of these products by prescribers and lay society, at the same time they are increasingly present in pharmacies and drugstores, increasing the therapeutic arsenal of these establishments. This study aims to analyze the labels of herbal medicines sold in a drugstore in the city of Manaus$\mathrm{AM}$, in relation to what is recommended by the current legislation of Anvisa. The present study is a sampling research with comparative data analysis of 35 herbal medicines, using data published by Anvisa referring to the labeling of herbal medicines. The present study demonstrated that not all medications follow the standardization of Anvisa, since the Braille system is largely lacking, which makes people with visual impairments unable to access it. The data presented show a significant amount of herbal medicine brands do not meet this essential demand, that is, the guarantee of access for the visually impaired to safe and rational therapy of herbal medicines, with only $29 \%$ of the analyzed medicines being compatible with what is recommended by ANVISA legislation. Works like this have an important role to be monitored in social demands, and should be further explored, since they provide an immense inspection service to regulatory bodies and lay society.
\end{abstract}

Keywords: Herbal medicines; Drugstore; Labeling; Herbal medicines.

\section{Resumen}

En los últimos años, el consumo de plantas medicinales y hierbas medicinales ha experimentado un notable aumento en el consumo en la sociedad brasileña. Esto se debe a que la seguridad que demuestran los estudios clínicos es su eficacia en el tratamiento de determinadas patologías. Además de la percepción de seguridad de estos productos por parte de prescriptores y la sociedad lega, al mismo tiempo están cada vez más presentes en farmacias y droguerías, aumentando el arsenal terapéutico de estos establecimientos. Este estudio tiene como objetivo analizar las etiquetas de los 
medicamentos herbales vendidos en una farmacia de la ciudad de Manaus-AM, en relación con lo recomendado por la legislación vigente de Anvisa. El presente estudio es una investigación por muestreo con análisis de datos comparativos de 35 medicamentos a base de hierbas, utilizando datos publicados por Anvisa que se refieren al etiquetado de medicamentos a base de hierbas. El presente estudio demostró que no todos los medicamentos siguen la estandarización de Anvisa, ya que el sistema Braille es en gran parte deficiente, lo que hace que las personas con discapacidad visual no puedan tener acceso. Los datos presentados muestran que una cantidad significativa de marcas de fitoterápicos no cubren esta demanda fundamental, es decir, la garantía de acceso de las personas con discapacidad visual a la terapia segura y racional de los fitoterápicos, siendo solo el $29 \%$ de los medicamentos analizados compatibles con lo que es recomendado por la legislación de ANVISA. Obras como esta tienen un papel importante a monitorear en las demandas sociales, y deben ser exploradas más a fondo, ya que brindan un inmenso servicio de inspección a los organismos reguladores y la sociedad laica.

Palabras clave: Hierbas medicinales; Farmacia; Etiquetado; Medicamentos a base de hierbas.

\section{Introdução}

Os medicamentos fitoterápicos foram utilizados por muitas eras como medicamentos de cura e de alívio. No passado como a medicina não era tão avançada, se fazia necessários os saberes a respeito de ervas medicinais, para que serviam, para dor tomar, como estancar sangue, para acalmar os nervos, entre tantas outras situações. Até então eram conhecidas como infusões e macerados, com o passar do tempo a medicina começou a evoluir como algo alternativo para a cura de muitas situações fazendo com que os conhecimentos a respeito de plantas fosse se tornando secundário (Marques et al., 2019).

Atualmente é possível ver que os medicamentos à base de ervas são muito utilizados na terapêutica moderna. Muitos ensinamentos de muitas plantas foram guardados aos longos do tempo principalmente por aqueles povos que viviam longe de cidade e a utilização de dinheiro era quase impossível, desta forma era necessário entender sobre cada planta, para que servia e onde se é encontrada e qual a forma correta de uso (Rogério, Ribeiro, 2021).

Muito ainda se discute sobre sua utilização, sendo que a cada dia que se passa novas fórmulas fitoterápicas estão surgindo. O que se observa é que em tempos atuais, estes tipos de medicamentos já começam a ser incluídos em inúmeros tratamentos, o que se redobra atenção para eles, diante disso é necessário que políticas de saúde sejam direcionadas para tal situação, uma vez que a população que faz sua utilização nem sempre utiliza a prescrição médica (Lombado, 2018).

O mercado farmacêutico começou a ter um olhar diferente para esses tipos de substância, começou a entender que algumas destas substâncias realmente serviam para o fim de cura, entretanto era difícil fazer uma recomendação sem uma análise científica, foi quando começou a surgir inúmeras pesquisas e testes no âmbito da etnofarmacologia, desta forma começou-se a entender inúmeros mecanismos de ação de plantas medicinais que até então eram desconhecidas (Prado, Matsuok \& Giotto, 2018).

Os medicamentos fitoterápicos começaram a ganhar seu espaço dentro de hospitais, farmácias e outros lugares, porém para que estes tipos de medicamentos entrassem nestes locais era necessário que ele tivesse um registro para que indicasse que ele realmente serviria para aquilo que fosse recomendado (Turmina et al., 2020).

A Anvisa no Brasil, começou a legalizar a utilização de medicamentos fitoterápicos, pois começou a ver através de inúmeras análises que estes medicamentos podem também ajudar no processo de recuperação do paciente, sendo assim instruções normativas para que estes tipos de medicamentos começassem a ser comercializados legalmente (Manfio, Junior, 2017).

Para que os medicamentos possuíssem validade era necessário que passassem por um controle rigoroso de informações e para que fossem comercializados da forma correta era necessário que se seguissem a instrução normativa $\mathrm{n}^{\circ} 02$ de 13 de maio de 2014 onde está a lista de medicamentos fitoterápicos aprovados pela Anvisa, também a resolução - RDC 71, de 22 de dezembro de 2009 que explica sobre a rotulagem de medicamentos fitoterápicos (Souza et al., 2019).

Mesmo com a quantidade de medicamentos fitoterápicos ainda pequena em relação aos medicamentos alopáticos, existe ainda uma considerável parcela de marcas que necessitam de ajustes quanto sua adequação legal (Esteves et al., 2020). Desta 
forma é necessário um controle de fiscalização a respeito destes medicamentos e a forma como são vendidos desde validade de registros até as próprias informações dos rótulos afinal (Vieira \& Pessoa, 2017).

As embalagens têm muito a dizer do medicamento, conforme as normas da Agência Nacional de Vigilância Sanitária (ANVISA) através da Resolução-RDC No 71, de 22 de dezembro de 2009 que se trata dos mais diversos rótulos de medicamentos no caso dos medicamentos fitoterápicos estão na seção XI nos artigos 52 e 53, também é amparada pela resolução específica (BRASIL, 2003. Ministério da Saúde, Agência Nacional de Vigilância Sanitária - ANVISA - resolução - RDC 333/2003).

Desta forma o presente estudo tem como objetivo geral analisar a conformidade das embalagens de produtos fitoterápicos de acordo com a RDC N 71, de 22 de dezembro de 2009 comercializados em uma drogaria da cidade de ManausAM, avaliando dessa forma a qualidade dos rótulos, com relação às possíveis inconformidades nos rótulos em comparação com o registro na ANVISA.

\section{Metodologia}

Foi realizado um estudo de pesquisa de campo de caráter comparativo, descritivo onde o objetivo foi analisar a adequação das informações contidas nos rótulos de 35 medicamentos fitoterápicos comercializados em uma drogaria da cidade de Manaus -AM conforme fluxo proposto na figura 1.

Para o estudo, foram selecionados 35 embalagens secundárias de medicamentos fitoterápicos disponíveis para venda em uma drogaria da região metropolitana de Manaus, sendo elas: Pasalix PI, Pasalix, Sintocalmy, Maracugina PI, Serenus, Calman, Seakalm, Sominex, Tensart, Calmphar PI, Maracuja, Prakalmar, Alcachofray, Alcachofra, Varivax, Venolise, Varicell, Bioflan, Centella, Fhitoss, Abrilar, Artroflan, Arlivry, Aremaz, Xarope de guaco, Umckan, Fisiotan, Litane, Soyfemme, Piascledine 300, Motore, Sonotabs, Isoflavine, Caloba e Inthos, todos nomes comerciais comercializados na referida drogaria.

Figura 1: Fluxograma de análise de conformidade dos 35 medicamentos fitoterápicos selecionados para essa revisão.

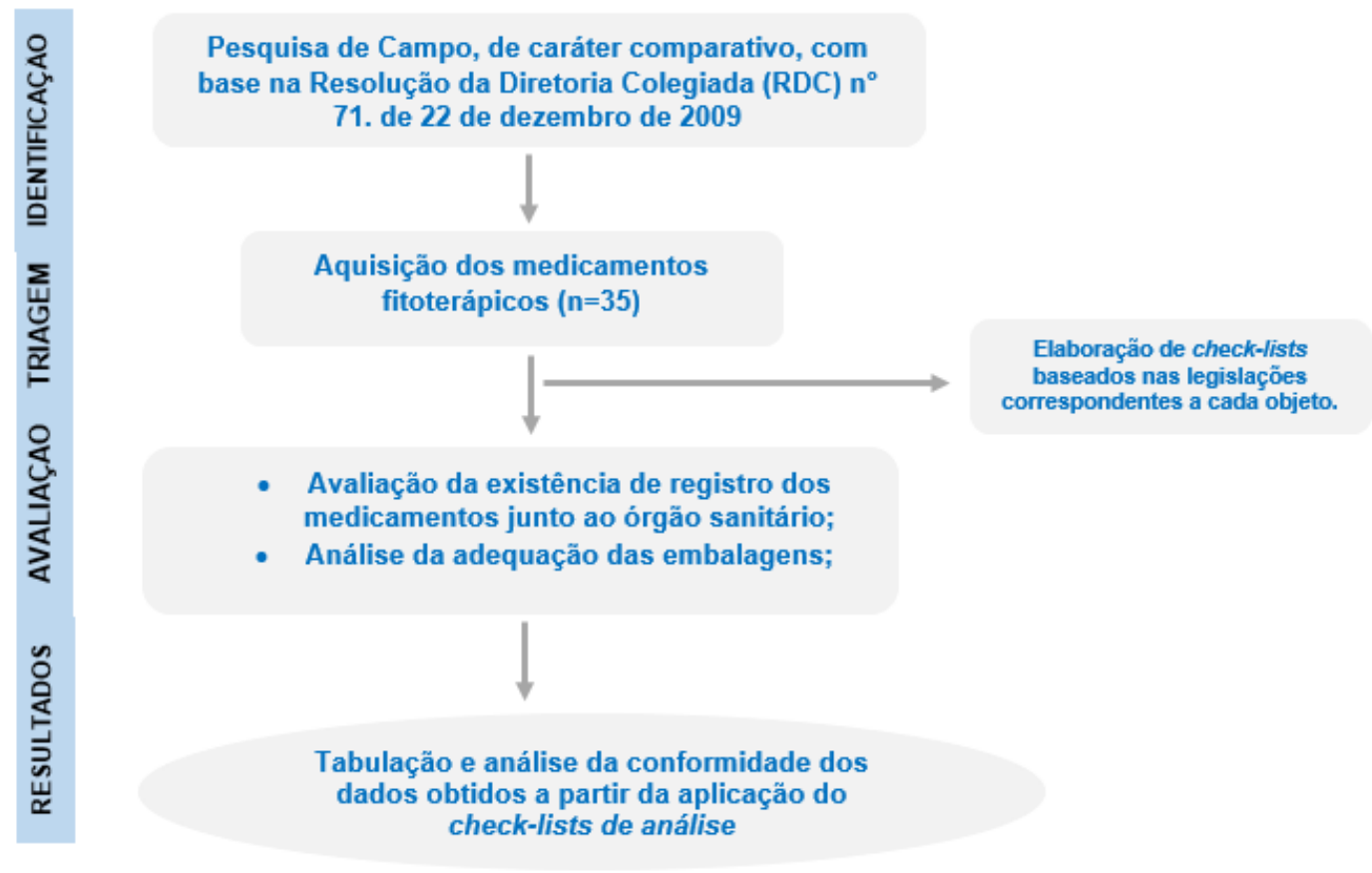

Fonte: Autores.

Os rótulos foram escolhidos de acordo com a planta encontrada no fármaco como princípio ativo, desta forma as plantas incluídas no estudo foram: Passiflora incarnta l., valeriana oficinalis, cynara scolymus l., aesculus hippocastanum l., melilotus 
officinalis, harpagophytun procumbers, cetella asiática, hetdera helix l., mikania glomerata, perlagonium sidoides, rhodiola rósea l., glycine max, cúrcuma longa, polidium leucatomos

Para a coleta de dados foi utilizado um Check-lists de informações de análise de acordo com o que preconiza a Resolução da Diretoria Colegiada (RDC) $\mathrm{n}^{\circ} 71$, de 22 de dezembro de 2009 contendo 17 perguntas de acordo com dados da Anvisa a respeito de medicamentos fitoterápicos (Nome comercial; $N^{o}$ de cadastro; M.S; Formula Farmacêutica; Planta medicinal; Concentração; Nome da marca; Restrição de destinatário; Data de validade de lote; Via de administração; CNPJ; Telefone da fábrica; Sistema em Braille; Medicamento fitoterápico; Letreiros; Peso da forma farmacêutica e Devidamente lacrado), o qual foi aplicado em cima dos 35 medicamentos selecionados (Quadro 1).

Quadro 1: Itens que serão avaliados de acordo com dados da Anvisa a respeito dos medicamentos fitoterápicos

\begin{tabular}{|c|c|}
\hline Nome comercial & Nome do medicamento em pelo menos 2 lados da embalagem. \\
\hline $\mathrm{N}^{\mathrm{o}}$ de cadastro & Número expedido pelo ministério da saúde \\
\hline M.S & Sigla ao lado esquerda do número de cadastro. \\
\hline Formula Farmacêutica & $\begin{array}{l}\text { Tecnologia usada para comportar a fármaco: Cápsula, Solução, Xarope, } \\
\text { Comprimido, Aerossol ou Creme }\end{array}$ \\
\hline Planta medicinal & Nome científico da planta que usada com extrato \\
\hline Concentração & Quanto de cada planta tem contido na forma farmacêutica. \\
\hline Nome da marca & Logo ou nome do fabricante \\
\hline Restrição de destinatário & $\begin{array}{l}\text { Os dizeres devem ser: uso adulto ou uso adulto e pediátrico acima de } 2 \text { anos ou } \\
\text { adulto e pediátrico acima de } 10 \text { anos ou uso adulto e pediátrico acima de } 12 \\
\text { anos. }\end{array}$ \\
\hline Data de validade de lote & Deve estar legível. \\
\hline Via de administração & USO ORAL (dependendo da forma farmacêutica) \\
\hline CNPJ & Cadastro Nacional de Pessoa Jurídica \\
\hline Telefone da fabrica & Número de telefone fixo com prefixo \\
\hline Sistema em braile & Em caso de embalagem secundária. \\
\hline Medicamentos fitoterápicos & Escrito na embalagem \\
\hline Letreiros & $\begin{array}{l}\text { Com dizer: TODO MEDICAMENTO DEVE SER MANTIDO FORA DO } \\
\text { ALCANCE DE CRIANÇAS }\end{array}$ \\
\hline Peso da forma farmacêutica & Peso total do conteúdo da embalagem \\
\hline Devidamente lacrado & Está em condições adequadas de armazenamento \\
\hline Consulta Anvisa & Se o Medicamento está regular. \\
\hline
\end{tabular}

Fonte: Autores.

\section{Resultados e Discussões}

Dos 35 medicamentos (Quadro 2) fitoterápicos analisados neste estudo, 25,71\% (9 medicamentos), eram medicamentos vendidos sob prescrição médica e 74,29\% (26) eram medicamentos isentos de prescrição médica. Em relação ao nome comercial, nome científico, forma farmacêutica, indicação terapêutica, os dados foram organizados de forma sistemática no Quadro 2. 
Quadro 2: Principais informações coletadas a partir dos rótulos de 35 medicamentos fitoterápicos analisados.

\begin{tabular}{|c|c|c|c|c|}
\hline Nome Comercial & Nome Científico & $\begin{array}{c}\text { Forma } \\
\text { Farmacêutica }\end{array}$ & Indicação Terapêutica & Categoria de Venda \\
\hline Pasalix PI & Passiflora Incarnata & $\begin{array}{l}\text { Comprimido } \\
\text { revestido }\end{array}$ & Insônia e ansiedade. & Venda livre \\
\hline Pasalix & $\begin{array}{l}\text { Passiflora Incarnata, } \\
\text { Crataegus rhipidophylla, } \\
\text { Salix alba l. }\end{array}$ & $\begin{array}{l}\text { Comprimido } \\
\text { revestido }\end{array}$ & Insônia e ansiedade. & Venda livre \\
\hline Sintocalmy & Passiflora Incarnata & $\begin{array}{l}\text { Comprimido } \\
\text { revestido }\end{array}$ & Insônia e ansiedade. & Venda livre \\
\hline Maracugina $P I$ & $\begin{array}{l}\text { Maracujá, Passiflora } \\
\text { Incarnata l. }\end{array}$ & $\begin{array}{l}\text { Comprimido } \\
\text { revestido }\end{array}$ & Insônia e ansiedade. & Venda livre \\
\hline Serenus & $\begin{array}{l}\text { Passiflora Incarnata, } \\
\text { Crataegus rhipidophylla, } \\
\text { flavonoides, Salix alba } l .\end{array}$ & $\begin{array}{l}\text { Comprimido } \\
\text { revestido }\end{array}$ & Insônia, estresse e tensão. & Venda livre \\
\hline Calman & $\begin{array}{c}\text { Passiflora Incarnata, } \\
\text { Crataegus/ Es pinheiro Alvar, } \\
\text { Salgueiro Branco }\end{array}$ & Solução oral & $\begin{array}{l}\text { Insônia, ansiedade, } \\
\text { irritabilidade. }\end{array}$ & Venda livre \\
\hline Seakalm & Passiflora Incarnata & $\begin{array}{l}\text { Comprimido } \\
\text { revestido }\end{array}$ & Insônia e ansiedade. & Venda livre \\
\hline Sominex & $\begin{array}{c}\text { Valeriana Oficinallis l., } \\
\text { Crataegus Oxicantha l., } \\
\text { Passiflora Incarnata. }\end{array}$ & $\begin{array}{l}\text { Comprimido } \\
\text { revestido }\end{array}$ & Ansiedade leve e insônia. & Venda livre \\
\hline Tensart & Passiflora Incarna $L$. & $\begin{array}{l}\text { Comprimido } \\
\text { revestido }\end{array}$ & $\begin{array}{l}\text { Ansiedade, irritabilidade, } \\
\text { Agitação Nervosa, insônia. }\end{array}$ & Venda livre \\
\hline Calmphar PI & Passiflora Incarna $L$. & $\begin{array}{l}\text { Comprimido } \\
\text { revestido }\end{array}$ & $\begin{array}{l}\text { Ansiedade, irritabilidade, } \\
\text { Agitação Nervosa, insônia. }\end{array}$ & Venda livre \\
\hline Maracujá & Passiflora Incarna $L$. & $\begin{array}{l}\text { Comprimido } \\
\text { revestido }\end{array}$ & $\begin{array}{l}\text { Desordem da Ansiedade, } \\
\text { irritabilidade, Agitação } \\
\text { Nervosa, insônia. }\end{array}$ & Venda livre \\
\hline Prakalmar & Passiflora Incarna $L$. & $\begin{array}{l}\text { Comprimido } \\
\text { revestido }\end{array}$ & $\begin{array}{l}\text { Insônia, ansiedade, } \\
\text { irritabilidade. }\end{array}$ & Venda livre \\
\hline Alcachofray & Cynara Scolymus L. & $\begin{array}{l}\text { Comprimido } \\
\text { revestido }\end{array}$ & $\begin{array}{l}\text { Facilita digestão e alivia } \\
\text { desconforto abdominal. } \\
\text { Gases e Náuseas resultante da } \\
\text { produção e eliminação da } \\
\text { bile. Diminuição do } \\
\text { colesterol. }\end{array}$ & Venda livre \\
\hline Alcachofra & Cynara Scolymus L. & $\begin{array}{l}\text { Comprimido } \\
\text { revestido }\end{array}$ & $\begin{array}{l}\text { Auxilia a digestão de } \\
\text { gorduras. }\end{array}$ & Venda livre \\
\hline Varivax & Aesculux Hippocastanum L. & $\begin{array}{l}\text { Comprimido } \\
\text { revestido }\end{array}$ & $\begin{array}{l}\text { Varizes, dor, inchaço nas } \\
\text { pernas e quadro de } \\
\text { insuficiência venosa crônica. }\end{array}$ & Venda livre \\
\hline Venolise & Melilotus Officinalis L. & $\begin{array}{l}\text { Comprimido } \\
\text { revestido }\end{array}$ & $\begin{array}{l}\text { Varizes, dor e nas pernas, } \\
\text { câimbras, coceiras e } \\
\text { inchaços. }\end{array}$ & Venda livre \\
\hline Varicell & Aesculux Hippocastanum L. & $\begin{array}{l}\text { Comprimido } \\
\text { revestido }\end{array}$ & $\begin{array}{l}\text { Dores nas pernas, sensação } \\
\text { de peso e cansaço, inchaços e } \\
\text { câimbras. }\end{array}$ & Venda livre \\
\hline
\end{tabular}




\begin{tabular}{|c|c|c|c|c|}
\hline Bioflan & Harpagophytum Procumbens & $\begin{array}{l}\text { Comprimido } \\
\text { revestido }\end{array}$ & $\begin{array}{l}\text { Alivio das dores articulares, } \\
\text { ação analgésica e } \\
\text { antiflamatória. }\end{array}$ & Venda livre \\
\hline Centella & Centella Asiática & $\begin{array}{l}\text { Comprimido } \\
\text { revestido }\end{array}$ & $\begin{array}{l}\text { Insuficiência venosa do } \\
\text { membros inferiores. }\end{array}$ & Venda livre \\
\hline Fhitoss & Hedera Helix L. & Líquido & Expectorante & Venda livre \\
\hline Abrilar & Hedera Helix $L$. & Líquido & Expectorante & Sob Prescrição \\
\hline Artroflan & Harpagophytum Procumbens & $\begin{array}{l}\text { Comprimido } \\
\text { revestido }\end{array}$ & $\begin{array}{l}\text { Alivio das dores articulares, } \\
\text { articulações moderadas e dor } \\
\text { lombar. }\end{array}$ & Venda livre \\
\hline Arlivry & Hedera Helix $L$. & Líquido & Expectorante & Sob Prescrição \\
\hline Aremaz & Hedera Helix $L$. & Líquido & Expectorante & Sob Prescrição \\
\hline Xarope de guaco & Mikania Glomerata L. & Líquido & $\begin{array}{l}\text { Expectorante e } \\
\text { broncodilatador. }\end{array}$ & Venda livre \\
\hline Umckan & Pelargonium sidoídes & Líquido & $\begin{array}{l}\text { Tratamento dos sintomas do } \\
\text { resfriado. }\end{array}$ & Sob Prescrição \\
\hline Fisiotan & Rhodiola Rósea L. & $\begin{array}{l}\text { Comprimido } \\
\text { revestido }\end{array}$ & $\begin{array}{l}\text { Aumento da capacidade física } \\
\text { e mental. }\end{array}$ & Venda livre \\
\hline Litane & Pelargonium sidoídes & Líquido & $\begin{array}{l}\text { Tratamento dos sintomas do } \\
\text { resfriado. }\end{array}$ & Venda livre \\
\hline Soyfemme & Glycine Max & $\begin{array}{l}\text { Comprimido } \\
\text { revestido }\end{array}$ & Climatérico & Sob Prescrição \\
\hline Piascledine 300 & $\begin{array}{l}\text { Persea Americana Mill, } \\
\text { Glycine Max L. Merr. }\end{array}$ & $\begin{array}{l}\text { Comprimido } \\
\text { revestido }\end{array}$ & Climatérico & Sob Prescrição \\
\hline Motore & Cúrcuma longa & $\begin{array}{l}\text { Comprimido } \\
\text { revestido }\end{array}$ & $\begin{array}{l}\text { osteoartrite e artrite } \\
\text { reumatoide, e tem ação anti- } \\
\text { inflamatória }\end{array}$ & Sob Prescrição \\
\hline Sonotabs & Valeriana Oficinallis $l$. & $\begin{array}{l}\text { Comprimido } \\
\text { revestido }\end{array}$ & Ansiedade leve e insônia. & Sob Prescrição \\
\hline Isoflavine & Glycine Max & $\begin{array}{l}\text { Comprimido } \\
\text { revestido }\end{array}$ & $\begin{array}{l}\text { Coadjuvante no alivio dos } \\
\text { sintomas do climatério }\end{array}$ & Venda livre \\
\hline Caloba & Pelargonium Sidídes DC & $\begin{array}{l}\text { Comprimido } \\
\text { revestido }\end{array}$ & $\begin{array}{l}\text { Tratamento dos sintomas do } \\
\text { resfriado. }\end{array}$ & Sob Prescrição \\
\hline Inthos & Polypodium Leucatomos & $\begin{array}{l}\text { Comprimido } \\
\text { revestido }\end{array}$ & $\begin{array}{l}\text { Irritação da pele agravada } \\
\text { pelo sol }\end{array}$ & Venda livre \\
\hline
\end{tabular}

Fonte: Autores.

A verificação do registro dos medicamentos fitoterápicos foi feita no site da Agência Nacional de Vigilância Sanitária (Anvisa) (https://consultas.anvisa.gov.br/\#/), utilizando o nome do produto e o Cadastro Nacional de Pessoa Jurídica (CNPJ) para agilizar a verificação. Na análise foram observados a existência do registro junto ao orgão fiscalizados e o seu prazo de validade. De acordo com a Lei $n^{\circ}$ 6.360/76 é obrigatório que todos medicamentos tenham registro no Ministério da Saúde para que sejam posteriormente colocados a venda e consumo da sociedade. Foi verificado que $100 \%$ dos medicamentos analisados tinha seu registro válido, sendo resultados compatíveis com outros autores (Maciel, 2013; Vieira \& Pessoa, 2017), o que mostra 
uma adequação geral, uma vez que a lei se fez um instrumento afim de proteger a presença de medicamentos falsificados ou sem registro no mercado geral. Entretanto fato esse que não exigem $100 \%$ da ausência desses medicamentos de origem duvidosa do comércio.

De uma forma geral a embalagem do medicamento é um instrumento importante na garantia da qualidade, eficácia e segurança dos medicamentos. Passando ao consumidor final segurança no uso desses produtos. Resolução da Diretoria Colegiada (RDC) $\mathrm{n}^{\circ}$ 71, de 22 de dezembro de 2009 define padrões de rotulagem que devem estar presentes nas embalagens dos medicamentos fitoterápicos. De modo geral pode-se alcançar cerca de 94,12\% de conformidades, ou seja 16 dos 17 itens analisados nessa revisão foram de acordo com a legislação vigente, e somente 5,88\%, ou seja, apenas 1 item foi não conforme. Entretanto, o item em questão foi em relação a obrigatoriedade do Sistema em Braille, onde sendo dos 35 medicamentos analisados, 71\% deles não apresentavam o sistema braille, conforme Quadro 3.

Quadro 3: Check-list dos dados exigidos legalmente na rotulagem das embalagens de medicamentos fitoterápicos de acordo com a Resolução da Diretoria Colegiada (RDC) n 71, de 22 de dezembro de 2009.

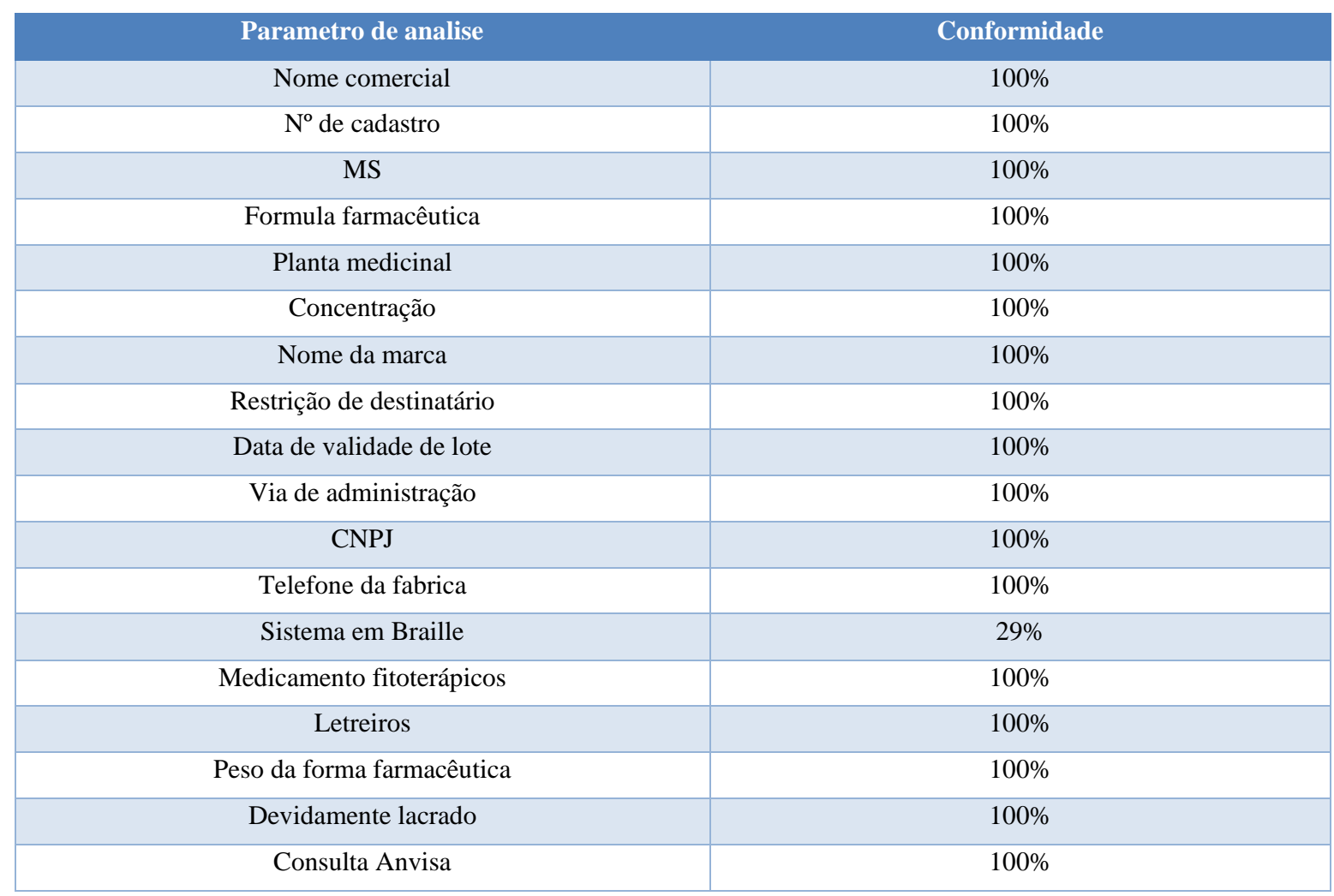

Fonte: Autores.

A análise da rotulagem de medicamentos é de imensa importância para os orgãos fiscalizadores, pois seguem atuando no monitoramento da qualidade do mercado e oferecendo subsídios legais aos orgãos responsáveis por regulamentar o setor (Copetti \& Griebeler, 2005).

Muitos autores afirmam que nossa legislação em relação a rotulagem já avançou e muito nos últimos anos (Copetti \& Griebeler, 2005; Maciel, 2013; Rigotto, 2016), apesar disso de acordo com Copetti \& Griebeler, 2005, ainda observa-se alguma inconformidades que devem ser verificadas, como a falta do sistema braille, visto em nosso estudo.

Para os autores Fujita, Machado \& Teixeira, 2014, a venda de um medicamento desta natureza vai além de um papel ilustrativo com apenas os dizeres de indicação, como é o caso de alguns comerciantes que fazem este tipo de venda, o que de 
fato apesar de ter legislação não se é proibido a venda destes produtos além da farmácia, já que os estudos para este tipo de medicamento apesar de muitos avanços ainda são lentos (Oliveira \& Ropek, 2016).

Este tipo de comercialização é algo que nunca irá acabar uma vez que um estudo a respeito de uma fórmula demora anos para que fique pronta, já o saber popular é algo que se passa de geração em geração. As farmácias de manipulação têm trabalhado muito para que este saber milenar seja considerado cientificamente certo, que estes tipos de medicamentos sejam realmente destinados a que eles são propostos em outras palavras deixem de ser placebo e passem a ser considerados realmente medicamentos fitoterápicos (Maciel, 2013).

Para Rigotto, 2016 e Júnior, Nascimento e Costa, 2019, é necessário que uma fiscalização e estudo bem maior a respeito destes medicamentos tantos os que são vendidos nas farmácias como os que são vendidos sem nenhum conhecimento técnicocientifico apenas vivência dos anos de utilização.

É necessário que os medicamentos fitoterápicos cheguem a todos os tipos de indivíduos para que a utilização de medicamentos seja algo universal e que todos possam entender o que estão usando, para que serve, quais seus efeitos. Um público que ainda apresenta uma grande difuldade de acesso é os deficientes visuais que até o momento so conhecem um sistema de interpretação que é o Braille.

Os dados apresentados demonstram que em $94,12 \%$ do estudo os medicamentos fitoterápicos estão com as informações minímas exigidas pela agência nacional de vigilância em saúde, entretanto quanto leva-se em consideração a questão sistema em Braille, observa-se que apenas 5,88\% apresentam uma não conformidade.

De acordo com Turmina et al., 2020, em novembro de 2007 a Agência Nacional de Vigilância em Saúde através do decreto 5.296/04, obrigou as indústrias farmacêuticas a disponibilizarem o sistema em Braille nas caixas de medicação, para gerar uma forma de inclusão para portadores de necessidade visuais.

Diante dos resultados, podemos inferir que existe a maior necessidade e controle de qualidade em relação aos rótulos desses medicamentos, para que se faça a inclusão segura da população deficiente visual para o uso seguro e corretos dos medicamentos fitoterápicos. Segundo Bezerra et. al., 2015, os dados da Anvisa servem de base para se entender toda a estrutura medicamentosa, uma vez que liberados para a população utilizar. Se faz necessária e urgente a adoção de novos recursos e tecnologias que busquem o aperfeiçoamento dos rótulos em embalagens de medicamentos pelos fabricantes, incluindo recursos gráficos, de impressão, de materiais e de dispositivos para rastrear, proteger e atestar a originalidade do produto.

\section{Conclusão}

O presente estudo demonstrou que os medicamentos fitoterápicos estão cada vez mais presentes na vida do ser humano, uma vez que o avanço dos estudos medicinais a respeito destes medicamentos terem avançado nas ultimas décadas.

O estudo demonstrou ainda que os medicamentos fitoterápicos assim como os medicamentos alópáticos tradicionais, precisam obedecer todas as normas que a agência de vigilância em saúde preconiza, afim de fornecer seguridade e padronização ao consumidor final.

Os dados apresentados mostraram também, uma grande deficiência na adoção do sistema de Braille (cerca de71\%), que é direcionada para o público de deficientes visuais, talvez isso seja devido que as atualizações de rotulagem serem bem recentes, cabendo as empresas, um maior tempo hábil para se adequarem a nova realidade.

Em dados gerais, os medicamentos em análise conseguiram atingir $94,12 \%$ de conformidade com a legislação preconizada pela Anvisa.

Portanto, o presente estudo demonstrou de como estudos de adequação com a legislação são ferramentas para os orgãos regulamentadores, fornecendo a estes, instrumentos e ferramentas de melhoria dos produtos a eles subordinados. Dessa forma 
espera-se encorajar mais trabalhos futuros que forneçam a sociedade resutados práticos na avaliação de conformidades, não somente de produtos fitoterápicos mas também dos medicamentos cormercializados de uma forma geral no âmbito nacional.

\section{Referências}

Bezerra, et al. (2015). Análise farmacoepidemiológica dos medicamentos fitoterápicos dispensados em uma Farmácia Comunitária no Sertão Paraibano. Revista Interdisciplinar em Saúde - RIS. 2(2): 177-195.

Brasil, 2000. Ministério da Saúde, Agência Nacional de Vigilância Sanitária - ANVISA - RESOLUÇÃO- RDC 17/2000 (Dispõe sobre o registro de medicamentos fitoterápicos.) Brasília. https://www.diariodasleis.com.br/busca/exibelink.php?numlink=1-9-34-2000-02-24-17

Brasil, 2003. Ministério da Saúde, Agência Nacional de Vigilância Sanitária - ANVISA - RESOLUÇÃO - RDC 333/2003 (Dispõe sobre rotulagem de medicamentos e outras providências.), Brasília.

Brasil, 2009a. Ministério da Saúde, Agência Nacional de Vigilância Sanitária -ANVISA - RESOLUÇÃO - RDC 71 , de 22 de Dezembro de 2009 (Estabelece regras para a rotulagem de medicamentos.), Brasília.

Brasil, 2011. Instrução normativa n 02 de 13 de maio de 2014 (Publica a "Lista de medicamentos fitoterápicos de registro simplificado" e a "Lista de produtos tradicionais fitoterápicos de registro simplificado" Brasília.

Copetti, F. B. \& Griebeler, S. A. (2005). Análise da adequação da rotulagem de medicamentos fitoterápicos. Infarma, v.17, n.7-9, p.60-64.

Esteves, et al. (2020). Medicamentos fitoterápicos: prevalência, vantagens e desvantagens de uso na prática clínica e perfil e avaliação dos usuários. Revista de Medicina, [S. 1.], v.99, n.5, p.463-472.

Fucina, G. (2012). Desenvolvimento de Medicamento Fitoterápico Semissólido Contendo Extrato Seco Padronizado de Sphagneticola trilobata (L.) Pruski [Dissertação]. Itajaí: Universidade do Vale do Itajaí, UNIVALI.

Fujita, P. L \& Machado, C. J. S., Teixeira, M. O. (2014). A bula de medicamentos e a regulação de suas configurações em termos de forma e conteúdo no Brasil. Saúde Soc. 23 (1); 277-292. DOI: 10.1590/S0104-12902014000100022.

Júnior, W. N. \& Nascimento, W. L., Costa, D. A. F. (2019). Análise da adequação de embalagens, bulas e peças publicitárias de medicamentos fitoterápicos. Infarma Ciências Farmacêuticas, v.31, n.1, p.54-62, 2019. doi:10.14450/2318-9312.v31.pp54-62

Lombardo, M. (2018). Potencial adverso de medicamentos fitoterápicos: um estudo com foco em medicamentos de registro simplificado. Rev Ciên Saúde. $3(1): 1-11$

Maciel, et al. (2013). Análise de rótulos de chás e folhas comercializadas em farmácias de produtos naturais, em Porto Seguro-BA. In: $64^{\circ}$ Congresso Nacional de Botânica. Belo Horizonte: Sociedade Botânica do Brasil.

Manfio, J. L. \& Junior, L. B. (2017). Desafios do desenvolvimento dos dossiês de registro de medicamentos fitoterápicos. Arq. Cienc. Saúde UNIPAR, Umuarama, v.21, n.1, p,47-52.

Marques, P. A., et al. (2019). Prescrição farmacêutica de medicamentos fitoterápicos. Brazilian Journal of Natural Sciences, [S. 1.], v.2, n.1, p.15.

Oliveira, A.C.D. \& Ropek, C.D. (2016). Os dez anos da Política Nacional de Plantas Medicinais e Fitoterápicos (PNPMF) e os principais entraves da cadeia produtiva de extratos vegetais e medicamentos fitoterápicos no Brasil. Rev Fitos. 10 (2): 95-219. DOI: 10.5935/24464775.20160015.

Prado, M. A. S., Matsuok, J. T., Giotto, A. C. (2018). Importância das Farmácias Vivas no âmbito da produção dos medicamentos fitoterápicos. Revista de Iniciação Científica e Extensão, [S. 1.], v.1, n.1, p.32-37.

Rigotto, et al (2016). A bula de medicamento: a importância da leitura das bulas. Rev Cient FAEMA. 7 (1):16-26.

Rogério, L. V. \& Ribeiro, J. C. (2021). Uso de plantas medicinais e medicamentos fitoterápicos em insônia: uma revisão bibliográfica. Brazilian Journal of Health and Pharmacy. v.3, n.2, p.35-44.

Souza, et al. (2019). A importância da atenção farmacêutica e farmácia clínica no uso racional de medicamentos fitoterápicos. Revista de Iniciação Científica e Extensão, [S. 1.], v. 2, n. Esp.1, p. 49.

Turmina, et al. (2020). Profissionais legalmente habilitados a prescreverem medicamentos fitoterápicos ou fitomedicamentos. Anais do Salão Internacional de Ensino, Pesquisa e Extensão, v.11, n.1.

Vieira, T.C. \& Pessoa, C.V. (2017). A importância das bulas para os medicamentos fitoterápicos. Anais da Mostra Científica da Farmácia. v.4. n.2. 